\title{
Game on: do children absorb sports sponsorship messages?
}

\author{
Simone Pettigrew ${ }^{1, *}$, Michael Rosenberg ${ }^{1}$, Renee Ferguson ${ }^{1}$, Stephen Houghton ${ }^{2}$ and \\ Lisa Wood ${ }^{3}$ \\ 'School of Sport Science, Exercise and Health (M408), University of Western Australia, 35 Stirling Highway, \\ Crawley, WA 6009, Australia: ${ }^{2}$ Centre for Child and Adolescent Related Disorders, University of Western \\ Australia, Crawley, Australia: ${ }^{3}$ School of Population Health (M431), University of Western Australia, \\ Crawley, Australia
}

Submitted 17 April 2012: Final revision received 10 August 2012: Accepted 16 November 2012: First published online 11 January 2013

\begin{abstract}
Objective: It is likely that there are substantial subconscious effects of organizations' efforts to associate their products with sport via sponsorships, but most research methods are unable to capture these effects. The present study employed a novel projective technique to explore children's implicit associations between popular sports and a range of sports sponsors.

Design: Children participated in an activity using magnets bearing the logos of numerous sports and sponsors. They were invited to arrange the magnets on a whiteboard without being advised that the activity related to sponsorship.

Setting: Perth, Western Australia.

Subjects: Children ( $n$ 164) aged 5-12 years.

Results: Three-quarters (76\%) of the children aligned at least one correct sponsor magnet with the relevant sport. Just over half the children (54\%) correctly matched the most popular sport (an Australian Football League team) with its relevant sponsor (a fast-food chain).

Conclusions: Given the unstructured nature of the projective task, the results provide some support for the argument that sports sponsorship can effectively reach child audiences. This is of concern given the current extent of sponsorship by alcohol and fast-food companies.
\end{abstract}

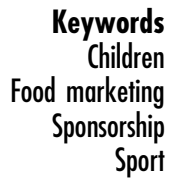

Sponsorship can allow access to specific market segments of interest that may be difficult to penetrate otherwise ${ }^{(1)}$. As organizations are increasingly restricted in their ability to advertise unhealthy products, sponsorship is taking on a more strategic role in their marketing activities ${ }^{(2)}$. In particular, sports sponsorship is recognized as a means by which industries that are constrained in their ability to directly target children can bypass existing advertising regulations ${ }^{(3-7)}$.

Sports sponsorship at both elite and club levels has been found to influence children's attitudes to unhealthy products ${ }^{(8,9)}$. For some time, concerns have been raised about this in relation to tobacco ${ }^{(10,11)}$ and alcohol $^{(3,12)}$. More recently, unhealthy foods have been identified as a further source of concern ${ }^{(9,13-15)}$. Previous studies have found that where sports that are popular with young people are sponsored by food and beverage companies, the sponsors' products are typically unhealthy ${ }^{(14,16)}$. Forming an association with a sporting body can be particularly advantageous for sponsors seeking to promote alcohol and unhealthy foods because of the natural synergies perceived by consumers between the 'heroic' sports person and these kinds of hedonic products ${ }^{(4,17)}$. On a more positive note, there may also be natural synergies between sports and health messages. In Australia, some health promotion organizations have sponsored sports and other events to communicate health messages and exclude unhealthy sponsors from entering into sponsorship $\operatorname{arrangements}^{(18-21)}$.

There has been limited research into the extent to which children are exposed to sponsorship messages in sports settings ${ }^{(22)}$ and the extent to which they assimilate such messages ${ }^{(4)}$. In their efforts to shed light on this issue, the few evaluations of the effects of product sponsorship on children have typically relied either on children's selfreports of the names of sponsors they can recall ${ }^{(8,23)}$ or measures of children's exposure to sponsorship messages in the media ${ }^{(24)}$. These studies have found that substantial numbers of children are routinely exposed to sponsorship messages, that they can readily nominate sponsors of particular sporting groups and that they typically view sponsoring organizations favourably.

Sponsorships are likely to influence product preferences and choices at both a conscious and non-conscious level. Non-conscious processing operates below the level of consciousness to assist with the detection of features and 
recognition of patterns in stimuli ${ }^{(25)}$. There is a growing body of evidence in the field of non-conscious consumer psychology $^{(26)}$ that demonstrates how product-related decision-making processes and resulting behaviours are influenced by automatic associations of which individuals are largely unaware ${ }^{(27,28)}$. Of particular relevance to the present study, product evaluation and choice have been found to be positively influenced by repeated exposure to product information that causes individuals to make automatic connections between the product and the environment in which the information is conveyed ${ }^{(29)}$. In this context, it is important to understand how exposure to sponsorship messages in a sports-related context may influence children's perceptions of desirable foods and beverages in order to inform future policy decisions relating to sponsorships that reach child audiences. In the first instance, this will require identifying the extent to which children exposed to sponsorship messages assimilate the suggested associations between the sponsor and the sponsee. There are, however, considerable methodological difficulties associated with measuring environmental factors that influence food attitudes and consumption ${ }^{(30)}$, and the methods used to date to capture the effects of sports sponsorship on children have been limited in their ability to assess the combined influence of both conscious and subconscious message assimilation.

To extend existing knowledge relating to the effects of sports sponsorship on child audiences, the present study utilized a novel projective technique to assess the extent to which children: (i) associate alcohol and fast-food brands with popular sports; (ii) associate specific health messages with popular sports; and (iii) experience contamination effects and hence potentially associate popular sports with general classes of products and/or health messages. The nature of the projective technique, the rationale for its selection and the process by which it was implemented are outlined below.

\section{Experimental methods}

Projective techniques involve subjects responding to ambiguous stimuli that can evoke varied reactions, thereby requiring them to project their own interpretations onto the stimuli ${ }^{(31)}$. This process can provide insight into individuals' subconscious knowledge and motivations that may be inaccessible via other means ${ }^{(32,33)}$. An unlimited range of projective exercises can be designed to elicit responses relating to a phenomenon of interest. More common examples include sentence completion exercises, word associations, picture response tests and collage construction ${ }^{(33,34)}$, while more unusual forms include joke telling and food tasting ${ }^{(35,36)}$.

The use of projective techniques for data collection brings both advantages and risks. For example, they are useful for sensitive issues or those about which individuals experience difficulty articulating their thoughts or feelings ${ }^{(37-39)}$. However, while projective techniques can often generate unique and useful information, highly unstructured exercises can fail to provide results specific to the topic of interest and interpretation of outputs can be problematic ${ }^{(34,35,39,40)}$. The very ambiguity that provides access to the subconscious can thus create validity issues.

Projective methods can be especially effective for use with children due to their less developed reasoning and communication skills ${ }^{(41,42)}$. Projective exercises are often inherently enjoyable ${ }^{(33,37,43)}$, which can be engaging for children and hence maintain their interest and attention throughout the data collection process. A potential disadvantage is that children can be eager to share their experiences with their peers, requiring the implementation of procedures to reduce their ability to confer with one another during task completion ${ }^{(44)}$.

To take advantage of the ability of projective techniques to access subconscious information, an activity was developed that allowed children to express associations they inferred between popular sports and a wide range of sponsoring organizations. A series of magnets was created that included eight sports/sports teams and twenty-three brands/messages. The selected sports and health messages were those that were funded by the organization sponsoring the research (the Western Australian Health Promotion Foundation) and the brands were primarily those that also sponsor these sports. The eight sports magnets represented two Western Australian amateur sporting groups (surfing and athletics) and six professional teams in the following sports: AFL (Australian Football League - two teams), rugby union, soccer, netball and cricket. Of the twenty-three brand/messages included in the activity, ten were for unhealthy foods and beverages, five were for alcohol, two were for other commercial sponsors (an airline and a food retailer) and six featured health messages. The latter related to smoking (two messages), alcohol consumption, fruit and vegetable consumption, physical activity and sun awareness. One of the smoking-related messages was represented three times, bringing the total number of potential magnets children could choose from to twenty-six. This was necessary because numerous sports were sponsored by this message, meaning that the children needed multiple magnets to choose from to give them the opportunity to make the correct association for all sports. The larger number of food and alcohol brands relative to other commercial sponsors reflected the funding body's particular interest in these sponsors because of their potential to encourage children to engage in unhealthy consumption behaviours.

Participant recruitment occurred at the Perth Royal Show in Western Australia in October 2011. The Show is an annual event that attracts around 500000 people. Attending parents were approached and invited to allow their children aged 5-12 years to participate in the magnet activity. This age group was selected to include children 

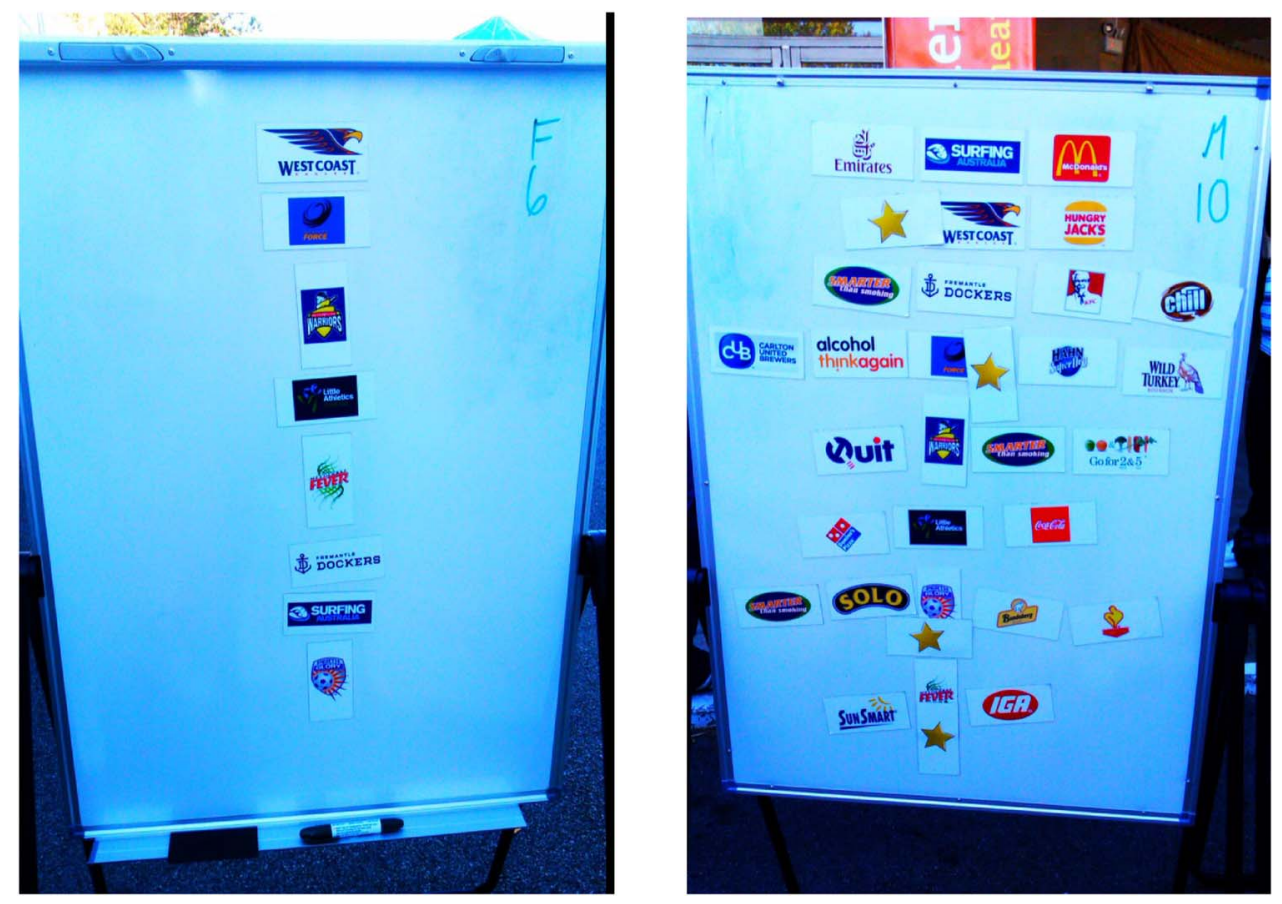

Fig. 1 (colour online) A whiteboard containing the sport magnets as initially presented to participants (left) and a whiteboard after task completion (right)

old enough to be able to engage effectively in the activity and young enough to be susceptible to companies' promotional activities due to a lack of awareness of and/or ability to withstand the persuasive intent of advertising $^{(42)}$. In their analysis of the implications of children's developmental stages on their perception of commercial messages, Wackman and Wartella(45) note that children aged 2-7 years are in a preoperational developmental stage that is characterized by an inability to distinguish between relevant and irrelevant stimuli and the tendency to assume that all information contained in a commercial message is true. Between 7 and 12 years of age, children are in a concrete-operational stage where they can prioritize between stimuli and appreciate that not all information conveyed in commercial messages is likely to be true. However, it is not until the formal-operational stage (adolescence) when children typically develop the skills required to mediate their own thoughts and take a critical stance towards commercial messages. Given these developmental differences, the inclusion of children in both the preoperational and concrete-operational stages allowed comparisons of the effects of sponsorship on children with different degrees of vulnerability.

As per the requirements of the University of Western Australia Human Ethics Committee which gave ethical approval for the study, parents were given an information sheet and both parents and children were required to sign consent forms to indicate their agreement to participate. As there was the potential for this to be a meaningless process for the youngest children, all children were verbally invited to participate in a magnet and whiteboard activity and were not pursued if they appeared reluctant. Following consent, each child was placed in front of two whiteboards, one containing the eight magnets for the sports/sports teams and the other containing all the other magnets bearing brand or health message logos. The order of placement of the various magnets was varied between participants to minimize any order effects. The children were instructed to keep the sports magnets in their given locations and place as many or as few of the other magnets as they wished on the whiteboard bearing the sports magnets. They were advised that they could place the brand/message magnets anywhere that they wished on the whiteboard containing the sports logos. No information relating to sponsorship was mentioned at any time during the activity. Once they had completed applying the sponsor magnets to the sport magnet whiteboard, the children were given four magnets featuring gold stars and told they could use some or all of these stars to show which of the sports, brands and/or messages they liked the most.

The pairs of whiteboards were arranged around the data collection area in such a way as to prevent children from being able to see each others' magnet placements. A digital photograph was taken of each whiteboard once the child had completed the activity (see Fig. 1). Age and gender information was recorded for each child.

During analysis, each photograph was examined to identify instances where brand/message magnets were 
placed in close proximity to the sports magnets. Each sport magnet was assessed for the number and type of magnets placed near it. The data were analysed using the statistical software package SPSS for Windows version 19. Descriptive statistics were used to analyse the demographic, sport, sponsor and 'star' data. Sponsor variables were grouped as 'unhealthy food/beverage', 'alcohol', 'corporate' or 'health message' sponsors. Chi-square analyses were conducted to assess for differences in correct sport-sponsor, starred sport-sponsor, sport-health message and sponsor groups by age group and gender. It was not possible to calculate specific probability rates because the study design allowed children to use as many or as few of the magnets as they chose and to place them in any location on the whiteboard. Once they had 'incorrectly' used a magnet, it was generally not available for use with the 'correct' sport, limiting their potential to make future accurate associations. However, the very large number of potential outcome combinations made the likelihood of children randomly placing sponsoring brand/messages adjacent to the relevant sports low.

\section{Results}

A total of 164 children participated in the study. Forty per cent were aged 5-8 years and 60\% were aged 9-12 years, with approximately equal gender distribution across and between the two age groupings (see Table 1). During data collection it was apparent that on the whole the children enjoyed participating in the activity and that they implicitly understood the notion of associating the provided brands/messages with the nominated sports. Almost all participants placed the sponsor magnets in linear alignment with the sports magnets, clearly demonstrating the relationships they perceived to exist between the nominated sports and the various brands/ messages. There was a small amount of overlapping of magnets by some participants, but this did not prevent straightforward identification of proximity between sports and brand/message magnets.

Table 2 ('Correct main sponsor(s)' column) shows the extent to which the participants made matches between sports and sponsoring brands/messages that were assessed as being 'correct'. Across the sample, 126 participants (76\%) correctly assigned at least one sponsor to at least one sport. A significantly higher proportion of children

Table 1 Sample characteristics: children ( $n$ 164) aged $5-12$ years, Perth, Western Australia, October 2011

\begin{tabular}{|c|c|c|c|c|c|c|}
\hline \multirow[b]{2}{*}{ Age } & \multicolumn{2}{|c|}{ Male } & \multicolumn{2}{|c|}{ Female } & \multicolumn{2}{|c|}{ Total } \\
\hline & $n$ & $\%$ & $n$ & $\%$ & $n$ & $\%$ \\
\hline 5-8 years & 31 & $37 \cdot 8$ & 34 & 41.5 & 65 & $39 \cdot 6$ \\
\hline $9-12$ years & 51 & $62 \cdot 2$ & 48 & 58.5 & 99 & $60 \cdot 4$ \\
\hline Total & 82 & $100 \cdot 0$ & 82 & $100 \cdot 0$ & 164 & $100 \cdot 0$ \\
\hline
\end{tabular}

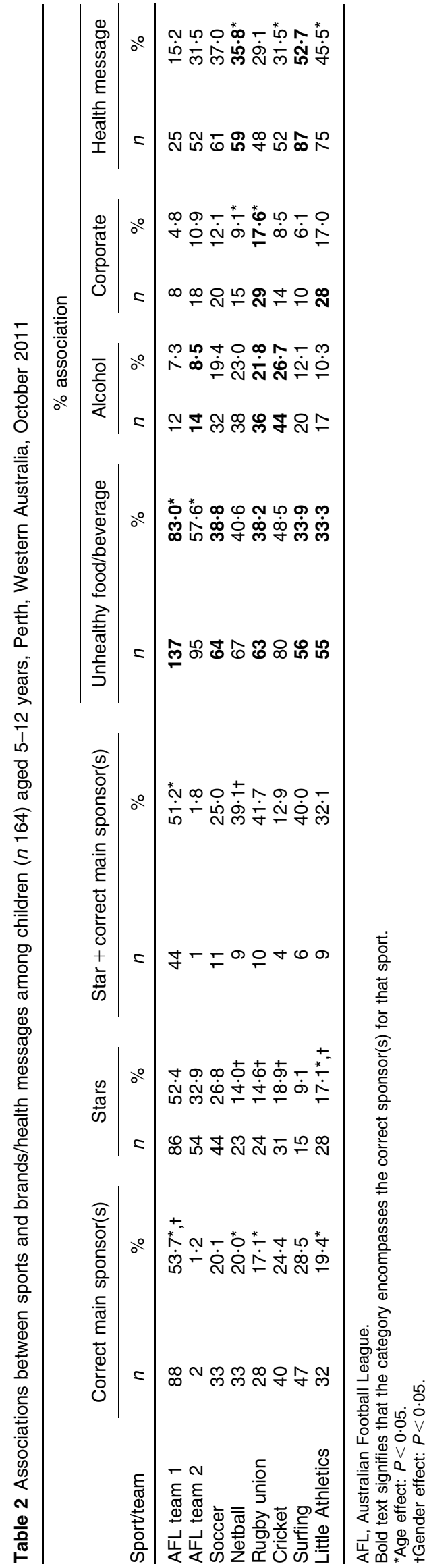


aged 9-12 years (83\%) than children aged 5-8 years $(68 \%)$ correctly assigned a sponsor to a sport $(P<0 \cdot 05)$. The outcomes varied from almost no participants correctly matching the sport and sponsor for one AFL team (1\%) to more than half the participants (54\%) making a correct match for the other AFL team. Of note is that the latter team was the first AFL team established in Western Australia (1987) and had a long-term sponsorship arrangement with a fast-food company (Hungry Jacks, known elsewhere as Burger King). By comparison, the other AFL team that exhibited a much lower accuracy rate was established more recently (1995) and had changed major sponsors during its shorter lifespan.

For four of the sports (netball, rugby union, Little Athletics and one of the AFL teams) there was a significant main effect of age, with older participants being more likely to match a correct sponsor. Only one sport/team, one of the two AFL teams, showed a significant main effect of gender, with boys more often matching correctly for this team than girls. For most sports, where participants allocated a star to a particular sport (Table 2, 'Stars' column), there was a higher rate of correct matching as indicated by a magnet bearing an actual sponsor being placed adjacent to the relevant sport magnet ('Star + correct main sponsor(s)' column). Age and gender had little effect on the relationship between correct matching and preference as indicated by star placement.

Participants' magnet placements were likely to have reflected both their knowledge of actual sponsors and their impressions of the kinds of brands/messages that 'go best' with particular sports. It was therefore of interest to identify any trends in associations to better understand how children may perceive some sports as being naturally aligned with certain kinds of brands/messages. Table 2 ( $\%$ association' columns) shows aggregated responses according to type of brand/message (categorized as unhealthy food/beverage, alcohol, corporate or health message). As indicated by the bolded text, the participants' associations were strongest for those categories that included the actual sponsor(s) for each sport. The number of magnets in each category is relevant when interpreting these results. For example, the correct fast-food sponsor for the first AFL team was nominated by approximately half of the participants, but $83 \%$ assigned at least one unhealthy food or beverage brand to this team. As ten of the twenty-six brand/message magnets related to this category (i.e. 38\%), this rate of matching suggests that the participants' association between this category of products and this team is strong.

The strong association between unhealthy foods/ beverages and many of the sports is concerning. It appears that contamination effects are occurring, possibly on multiple levels. Contamination in this context refers to when individuals' judgements or behaviours are affected by mental processes of which they are either unaware or unable to control ${ }^{(46)}$. In some instances the national teams were sponsored by fast-food companies (e.g. cricket), and it appears that the association effects in operation for the national team may have transferred to the Western Australian teams. In the case of the two AFL teams, the long-standing sponsorship of one team by a fast-food company may have resulted in the participants generalizing the overall association to both AFL teams. Of note is that the participants had access to a larger number of magnets relating to unhealthy foods and beverages compared with the other product categories, which may have skewed the responses towards this category. However, this distribution reflects actual sponsorship patterns and hence was unavoidable. Furthermore, there was a counteracting force in that very few of the participants used all the magnets provided, instead selectively choosing those that they felt were most appropriate for each type of sport.

The results demonstrate that some sports have healthier associations than others. For example, even though Little Athletics is not currently sponsored by a health agency, almost half of the study participants assigned at least one health message to this sport. This suggests that health promotion messages could be used effectively in this sporting context to capitalize on the existing strong association with healthiness. In addition, the associations between each sport and health messages were generally substantial, indicating that children are likely to be receptive to aligning health sponsorships with sport in general, as well as with particular sports and sports teams.

Table 2 ('Stars' column) shows that most of the sports were allocated stars by substantial numbers of participants. Certain fast-food restaurants, namely Hungry Jacks ( $n$ 42, 25.5\%), McDonald's ( $n$ 31, 18.8\%) and KFC ( $n$ 20,12.1\%), also received relatively large numbers of stars (not shown in Table 2). To a lesser extent, some non-alcoholic beverages were assigned as favourites, including Powerade ( $n 16,9 \cdot 7 \%$ ), Chill milk drinks ( $n 15$, $n 9 \cdot 1 \%)$, Coca Cola $(n 12,7 \cdot 3 \%)$ and Solo ( $n 11,6 \cdot 7 \%)$. Of particular interest is that two of the health messages had a degree of popularity: Go for 2 \& 5 ( $n$ 19, 11.5\%) and Smarter than Smoking ( $n$ 12, $7 \cdot 3 \%)$.

\section{Discussion and conclusions}

The projective technique employed in the present study appeared to be a productive method of exploring children's implicit associations between popular sports and the products and messages promoted via sports sponsorships. The results indicate that sports sponsorships may be an effective means of targeting children with promotional messages. The outcomes are generally consistent with previous Australian work that found that approximately half of the children sampled could correctly nominate the sponsor of their favourite professional sports team ${ }^{(8)}$. Although the children in the present study were not explicitly asked to identify sponsors 
during the projective task, three-quarters of the children accurately associated at least one of the nominated sports with the relevant sponsoring brand/message. The results also support the very limited previous research that has examined the impact of 'favourite sport' status on sponsorship awareness ${ }^{(47)}$, as correct matching rates were typically higher among children nominating a particular sport as among their favourites. Association effects thus appear to be occurring, demonstrating the need for advertising regulations to include specific reference to sports sponsorships.

Along with the potential to build preference through familiarity $^{(8,29)}$, there are other possible detrimental consequences of sports sponsorship by companies promoting unhealthy products that have yet to be fully appreciated. For example, while sponsors aim to promote their particular brand of food or beverage to increase sales and market share, there is evidence that food promotions can also influence children's preferences in relation to the overall food category ${ }^{(48)}$. The results of the present study provide some support for this contention, finding that even children who did not correctly identify the actual product sponsor for a sport or team often associated it with another product in the same product category. In addition, recent work has demonstrated that pairing an unhealthy food with a healthy food decreases estimates of energy content ${ }^{(49)}$ and increases the likelihood of the unhealthy food being consumed ${ }^{(50)}$. It is possible that repeatedly pairing unhealthy foods and beverages with healthy activities such as sport may have a similar contamination effect by causing individuals to incorrectly attribute healthy characteristics to unhealthy foods and beverages and/or to perceive that regularly consuming these items after participating in sport is part of a 'balanced' approach to life ${ }^{(51)}$. Further research is required to assess the extent to which these outcomes may be occurring and projective methods may be useful in obtaining access to the conscious and subconscious mechanisms that are at play.

On a more positive note, health sponsorships are a promising new area that requires further research to assess the potential to reach target audiences ${ }^{(19,20)}$. The results of the present study suggest that health message communication via sports sponsorships may be effective in reaching children and creating positive attitudes towards the messages. The natural synergies that appear to exist between sports sponsorship and health-promoting messages could be more effectively utilized to communicate with target audiences. Such efforts would also seem to be warranted by the growing trend for commercial organizations to incorporate healthy lifestyle messages into their brand communications to portray themselves in a favourable light ${ }^{(52)}$. The inclusion of child stepometers (akin to pedometers) with McDonald's Happy Meals sold in the UK in the lead up to the 2012 London Olympics is an example of this contradiction $^{(53)}$. There is potential for children to become confused if healthy lifestyle messages or imagery are promoted by the marketers of unhealthy products, suggesting the need for frequent and consistent health messages to be disseminated by reputable health agencies to ensure accurate information is being received. As commercial organizations increasingly incorporate sponsorship activities into their communications portfolios, it may benefit health agencies to adopt a similar approach to maximize their ability to broadly disseminate health messages. However, this also suggests the need for future research into the incremental and cumulative effects of children being bombarded with promotional messages via sports sponsorships ${ }^{(54)}$. It is unknown the extent to which healthy lifestyle messages delivered in sporting contexts can cancel out or be neutralized by accompanying messages for unhealthy foods and beverages.

The present results appear to provide some support for the argument that limiting children's exposure to the sponsorship messages of companies promoting unhealthy foods and beverages is an important element of public policy efforts to reduce child obesity and enhance child health ${ }^{(7,8)}$. Public awareness of these issues is growing, which is likely to translate into increased support for restrictions on sports sponsorship. For example, in recent years public support has grown in Australia for banning sports sponsorship by alcohol companies ${ }^{(55)}$, and currently around half the population endorses this approach ${ }^{(56)}$. This level of support needs to be considered in the light of the high significance of alcohol in Australian culture ${ }^{(57,58)}$ and appreciated as an encouraging indication of the potential for more stringent regulations around sports sponsorship across a range of unhealthy products. There is limited research on public support for banning sports sponsorship by companies promoting unhealthy food products, although initial indications are that parents in particular are likely to agree with such restrictions ${ }^{(9)}$.

To conclude, concerns relating to the ability of sports sponsorships to reach children appear well-founded. Many of the children in the present study correctly associated specific brands with the sports receiving sponsorship funding from these companies. While sponsors may argue that they are not intentionally targeting children, it is clear that their efforts are producing this 'unintended' consequence and that as a result they should come under closer scrutiny.

\section{Acknowledgements}

Sources of finding: This work was supported by the Western Australian Health Promotion Foundation. Conflicts of interest: There are no conflicts of interest to report. Authors' contributions: S.P. conceptualized the study and drafted much of the manuscript; M.R. and R.F. analysed the data; S.H. and L.W. assisted with data interpretation; and all authors were involved in the paperwriting process. 


\section{References}

1. Ling PM, Haber LA \& Wedl S (2010) Branding the rodeo: a case study of tobacco sports sponsorship. Am J Public Health 100, 32-41.

2. Kin F, Lian TY \& Yoon YC (2010) How the tobacco industry circumvented ban on tobacco advertising, promotion and sponsorship: observations from selected ASEAN countries. Asian J WTO Int Health Law Policy 5, 449-466.

3. Hastings G \& Sheron N (2011) Alcohol marketing to children: a new UK private member's bill provides a simple, clear, and effective way forward. BMJ 342, 1767.

4. McDaniel SR \& Mason DS (1999) An exploratory study of influences on public opinion towards alcohol and tobacco sponsorship of sporting events. J Serv Mark 13, 481-499.

5. Munro G \& De Wever J (2008) Culture clash: alcohol marketing and public health aspirations. Drug Alcohol Rev 27, 204-211.

6. Nicholson M \& Hoye R (2009) Reducing adolescents' exposure to alcohol advertising and promotion during televised sports. J Am Med Assoc 301, 1479-1482.

7. Sherriff J, Griffiths D \& Daube M (2010) Cricket: notching up runs for food and alcohol companies? Aust N Z J Public Health 34, 19-23.

8. Kelly B, Baur LA, Bauman AE et al. (2011) 'Food company sponsors are kind, generous and cool': (mis)conceptions of junior sports players. Int J Behav Nutr Phys Act 8, 95.

9. Kelly B, Baur LA, Bauman AE et al. (2012) Restricting unhealthy food sponsorship: attitudes of the sporting community. Health Policy 104, 288-295.

10. Chen X, Cruz TB, Schuster DV et al. (2002) Receptivity to protobacco media and its impact on cigarette smoking among ethnic minority youth in California. $J$ Health Commun 7, 95-111.

11. Holman CDJ, Donovan RJ, Corti B et al. (1997) Banning tobacco sponsorship: replacing tobacco with health messages and creating health-promoting environments. Tob Control 6, 115-121.

12. Kaskutas LA (1993) Changes in public attitudes toward alcohol control policies since the warning label mandate of 1988. J Public Policy Mark 12, 30-37.

13. Kelly B, Baur LA, Bauman AE et al. (2011) Tobacco and alcohol sponsorship of sporting events provide insights about how food and beverage sponsorship may affect children's health. Health Promot J Aust 22, 91-96.

14. Kelly B, Baur LA, Bauman AE et al. (2011) Role modelling unhealthy behaviours: food and drink sponsorship of peak sporting organisations. Health Promot J Aust 22, 72-75.

15. Kelly B, Baur LA, Bauman AE et al. (2011) Food and drink sponsorship of children's sport in Australia: who pays? Health Promot Int 26, 188-195.

16. Maher A, Wilson N, Signal L et al. (2006) Patterns of sports sponsorship by gambling, alcohol and food companies: an internet survey. BMC Public Health 6, 95.

17. Crompton JL (1993) Sponsorship of sport by tobacco and alcohol companies: a review of the issues. J Sport Soc Iss 17, 148-167.

18. Corti B, Holman CDJ, Donovan RJ et al. (1995) Using sponsorship to create healthy environments for sport, racing and arts venues in Western Australia. Health Promot Int 10, 185-197.

19. Lynch BM \& Dunn J (2003) Scoreboard advertising at sporting events as a health promotion medium. Health Educ Res 18, 488-492.

20. Madill J \& O'Reilly N (2010) Investigating social marketing sponsorships: terminology, stakeholders, and objectives. J Bus Res 63, 133-139.

21. Corti B, Holman CDJ, Donovan RJ et al. (1997) Warning: attending a sport, racing or arts venue may be beneficial to your health. Aust N Z J Public Health 21, 371-376.
22. Carter MA, Edwards R, Signal L et al. (2012) Availability and marketing of food and beverages to children through sports settings: a systematic review. Public Health Nutr 15, 1373-1379.

23. Aitken PP, Leathar DS \& Squair SI (1986) Children's awareness of cigarette brand sponsorship of sports and games in the UK. Health Educ Res 1, 203-211.

24. Kent MP, Dubois L \& Wanless A (2011) Food marketing on children's television in two different policy environments. Int J Pediatr Obes 6, e433-e441.

25. Kihlstrom JF (1987) The cognitive unconscious. Science 237, 1445-1452.

26. Chartrand TL \& Fitzsimons GJ (2011) Nonconscious consumer psychology. J Consum Psychol 21, 1-3.

27. Chartrand TL, Huber J, Shiv B et al. (2008) Nonconscious goals and consumer choice. J Consum Res 35, 189-201.

28. Fitzsimons GM, Chartrand TL \& Fitzsimons GJ (2008) Automatic effects of brand exposure on motivated behavior: how Apple makes you 'think different'. J Consum Res 35, 21-35.

29. Berger J \& Fitzsimons G (2008) Dogs on the street, pumas on your feet: how cues in the environment influence product evaluation and choice. J Mark Res 45, 1-14.

30. Lytle LA (2009) Measuring the food environment: state of the science. Am J Prev Med 36, 4 Suppl., S134-S144.

31. Rogers EM \& Beal GM (1958) Projective techniques in interviewing farmers. J Mark 23, 177-179.

32. McGrath MA, Sherry JF \& Levy SJ (1993) Giving voice to the gift: the use of projective techniques to recover lost meanings. J Consum Psychol 2, 171-191.

33. Rook DW (1988) Researching consumer fantasy. Res Consum Behav 3, 247-270.

34. Donoghue $S$ (2000) Projective techniques in consumer research. J Fam Ecol Consum Sci 28, 47-53.

35. Richman J (1996) Jokes as a projective technique: the humor of psychiatric patients. Am J Psychother 50, 336-346.

36. Pettigrew S \& Charters S (2008) Tasting as a projective technique. Qual Mark Res 11, 331-343.

37. Belk RW, Ger G \& Askergaard S (2003) The fire of desire: a multisited inquiry into consumer passion. J Consum Res 30, 326-351.

38. Day E (1989) Share of heart: what is it and how can it be measured? J Consum Mark 6, 5-12.

39. Hussey M \& Duncombe N (1999) Projecting the right image: using projective techniques to measure brand image. Qual Mark Res 2, 22-30.

40. Levy SJ (1985) Dreams, fairy tales, animals, and cars. Psychol Mark 2, 67-81.

41. Durkin K \& Houghton S (2000) Children's and adolescents' stereotypes of tattooed people as delinquent. Legal Criminol Psychol 5, 153-164.

42. John DR (1999) Consumer socialization of children: a retrospective look at twenty-five years of research. J Consum Res 26, 183-213.

43. Zober M (1955) Some projective techniques applied to marketing research. J Mark 20, 262-268.

44. MacGregor A, Currie C \& Wetton N (1998) Eliciting the views of children about health in schools through the use of the draw and write technique. Health Promot Int 13, 307-318.

45. Wackman DB \& Wartella E (1977) A review of cognitive development theory and research and the implication for research on children's responses to television. Commun Res 4, 203-224.

46. Wilson TD \& Brekke N (1994) Mental contamination and mental correction: unwanted influences on judgements and evaluations. Psychol Bull 116, 117-142.

47. Charlton A, While D \& Kelly S (1997) Boys' smoking and cigarette-brand-sponsored motor racing. Lancet 350, 1474. 
48. Cairns G, Angus K \& Hastings G (2009) The Extent, Nature and Effects of Food Promotion to Children: A Review of the Evidence to December 2008. Prepared for the World Health Organization. Stirling: Institute for Social Marketing, University of Stirling \& The Open University.

49. Chernev A \& Gal D (2010) Categorization effects in value judgments: averaging bias in evaluating combinations of vices and virtues. J Mark Res 47, 738-747.

50. Wilcox K, Vallen B, Block L et al. (2009) Vicarious goal fulfillment: when the mere presence of a healthy option leads to an ironically indulgent decision. J Consum Res 36, 380-393.

51. Hoek J \& Gendall P (2006) Advertising and obesity: a behavioral perspective. J Health Commun 11, 409-423.

52. Kraak VI, Kumanyika SK \& Story M (2009) The commercial marketing of healthy lifestyles to address the global child and adolescent obesity pandemic: prospects, pitfalls and priorities. Public Health Nutr 12, 2027-2036.
53. Clark M \& Brownell R (2012) The Obesity Games. The inside track on the marketing strategies of Olympic food and soft drink sponsors, and the sponsorship deals behind them. London: Children's Food Campaign, SUSTAIN; available at http://www.sustainweb.org/resources/files/ reports/The_Obesity_Games.pdf

54. Clarkson J (2010) Time to get tough on unhealthy sponsorships. Health Promot J Aust 21, 164-165.

55. Wilkinson C, Room R \& Livingston M (2009) Mapping Australian public opinion on alcohol policies in the new millennium. Drug Alcohol Rev 28, 263-274.

56. Tobin C, Moodie RA \& Livingstone C (2011) A review of public opinion towards alcohol controls in Australia. BMC Public Health 11, 58.

57. Ministerial Council on Drug Strategy (2006) National Alcohol Strategy 2006-2009. Canberra: Commonwealth of Australia.

58. Pettigrew S (2002) A grounded theory of beer consumption in Australia. Qual Mark Res 5, 112-122. 